\title{
Justification of the Concept of Mobile Educational Spaces: a Study on Typology and Sustainability
}

\author{
Julija Aleksić, Saja Kosanović, University of Priština; Dragan Komatina, University of Montenegro; \\ Eva Vaništa Lazarević, University of Belgrade
}

\begin{abstract}
The overall human progress continuously stimulates the transformation of the notion of architecture and enhances the development of new architectural forms. In line with the thesis that only sustainable architecture allows the fulfilment of contemporary requirements to full extent, this paper explores the variety of developed mobile educational spaces, classifies them into types and analyses their sustainability aspects. The analysis aims to define the cases and needs to which mobile educational spaces respond best, i.e. according to which their utilization is justifiable. The results open a new research debate on the relationship between sustainability and the duration of utilization.
\end{abstract}

Keywords - Typology of mobile educational spaces, social-pedagogical-physical interrelations, ecological considerations, economic sustainability.

Various architectural manifestations of overall human progress arose with the time; technological impact on newly developed forms is noticeable since the beginning of industrialization. Traditional, known forms, among them the "classical classroom" - basic immovable physical unit intended for teaching and learning, have been examined and criticized, and the alternatives were offered.

Leander et al. argue that "if mobilities of learning are new in some fashion, then part of this newness is conceived in relation to something familiar and conventional: the classroom. The classroom is significant not just as a material location in which education research is located (along with the laboratory, which it sometimes reproduces) but also as a conceived or imagined space - an imagined geography of a particular kind" $[1,331]$. Mobile educational spaces may hence be brought into relation with new mobile educational concept.

Although considered as highly technological and dependable rather on devices and cyber space than on defined physical context, the mobile educational concept may as well be applied through space movement. Additionally, mobility enhancement accounts for one of the major goals in contemporary teaching and learning. The effectiveness of the idea rationally increases with creation of the linkages between architecture and education by using innovative design solutions [2], i.e. with the shift from static to dynamic, mobile educational spaces. "The way we inhabit the world is also in flux-lifestyle, working patterns and sustainability issues are fundamentally altering the way we use buildings and the role that they play in society and the shaping of the world's environment. It is therefore not surprising that a building type that seems to respond to change rather than resist it seems to possess a new relevance" [3].

While designing conventional educational spaces, the architect is challenged to adapt a project to well-defined users' requirements and to respect given context. Oppositely, mobile spaces are characterised by spontaneity, adaptation to atypical condi- tions and limit overcoming. Portable buildings represent crucial part of architectural design output, one that influences and is influenced by the form and construction of all architecture [3]. "It is a type of architecture that has unique attributes which enable it to provide appropriate solutions in difficult situations." [3] "Portable buildings can be found in all spheres of human activity. Yet it is only in a small percentage of these cases that the building has been designed specifically for that purpose. This can be seen a result of one advantage of the type - flexibility and diversity of purpose - yet it is also certainly one of the reasons portable buildings are often not generally recognized as an area of relevant architectural concern" [3, 5].

The quality of physical environment reflects the quality of learning [2], and mobile educational environments are no exception to that. In order to justify application of the concept of mobile educational spaces in architectural practice, which is the main research aim, it is necessary to explain the need for such structures in the first place, i.e. to justify their social sustainability. In this respect, the paper proposes typological classification of mobile educational spaces in regard to intended purpose and gives the description of each main defined type. The classification is based on comprehensive analysis and comparison of numerous examples of world-wide developed mobile educational objects, and the presentation of the best-practice cases. The paper further explores environmental and economic sustainability of mobile educational spaces and their impact on health; suitable research methods - life cycle assessment and cost-benefit analysis are employed for this purpose. The synthesis of the study and derived conclusions finally justify the concept of mobile educational spaces, and at the same time propose to direct their application for temporary, periodical or short-lasting educational purposes and activities.

\section{TyPOLOGICAL CLASSIFICATION AND DESCRIPTION}

Mobile architecture aims to provide flexible response to changing situations in use, operation or location [4]. The idea, however, is not new; the examples of portable structures which are easily moved from one physical context to another may be found in distant history. By describing the analogy between traditional Bedouin tent and contemporary aircraft carrier, where both are seen as moving homes existing in today's world, Kronenburg notes that moving buildings are among the earliest human-made artefacts, predating vehicles $[3,1]$. Apart from primal housing function, today mobile spaces are used for various purposes, inter alia for all levels of formal education (from kindergarten to university level), as well as for informal (or less formal) educational concepts. 


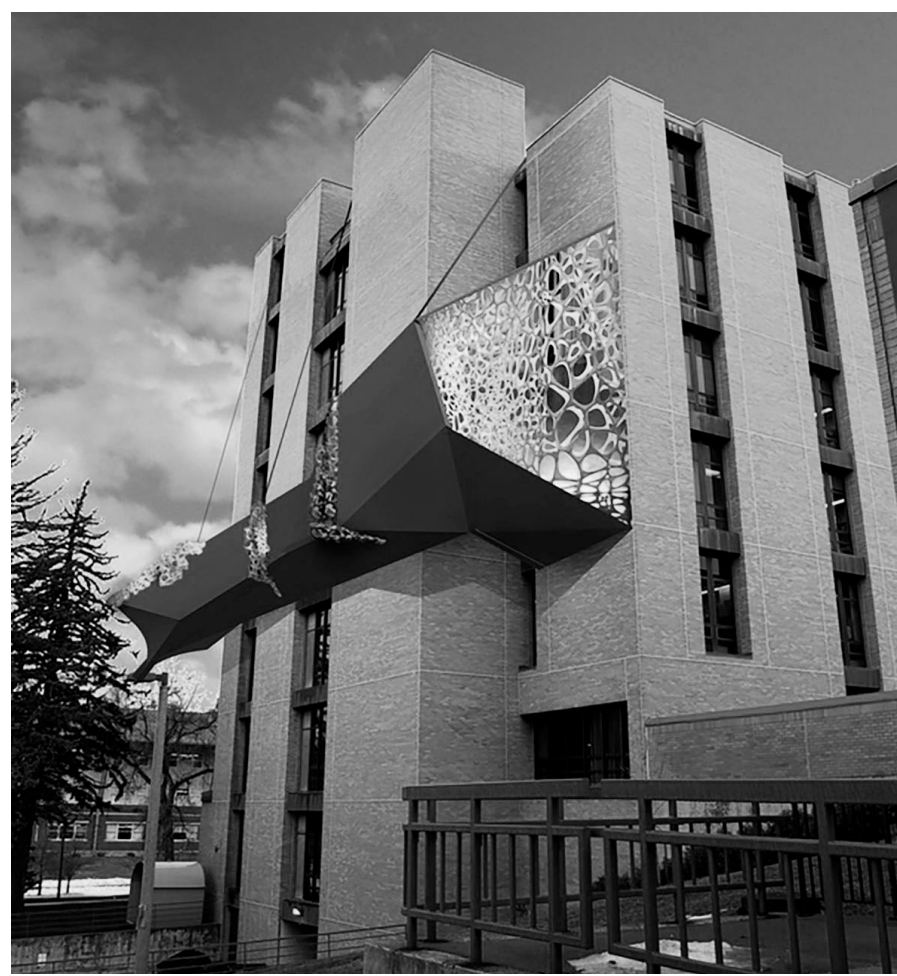

Fig.1. Design parasite [source: zachgeorgeworks.com].

The purpose of mobile educational space usually is well-reasoned, representing either a response to crisis conditions, a solution that allows the inclusion of new technology into educational process, a reflection of changed socio-cultural and educational demands (such as curriculum specialisation, development of experimental or on-field learning, instalment of business incubators within an existing environment), or a resolution of functional problem caused by the lack of existing space. No matter the reason, the portable design is considered as quick and feasible solution.

By analysing the purpose, i.e. the intended function, the following types of mobile educational spaces can be identified: extension to existing space, such as additional prefabricated classrooms or parasite structures; new permanent structures of larger scale; mobile spaces for crisis cases; mobile spaces for specialized educational forms, such as experimental learning; and spaces for community based learning. The case of "space in space" where micro-structural educational spots are embodied within permanent existing physical context can also be treated as a form of mobile educational space. Parasitic structures, mobile spaces for crisis/ emergency cases and the spaces for community based learning are the types that are attracting the greatest architectural interest.

Design parasite (Fig. 1) represents a special form of extension to existing space with perceptive size varying from street furniture to a building. Pit et al. describe design parasites as structures that are able of landing in many places, without actually critically approaching these locations. "Their mobile nature gives them a lack of engagement. Their surprising appearance is not matched by an equally interesting opinion on urban or architectural themes" [5]. Marini [6] notices differences among parasitical organism and the host in terms of form and space

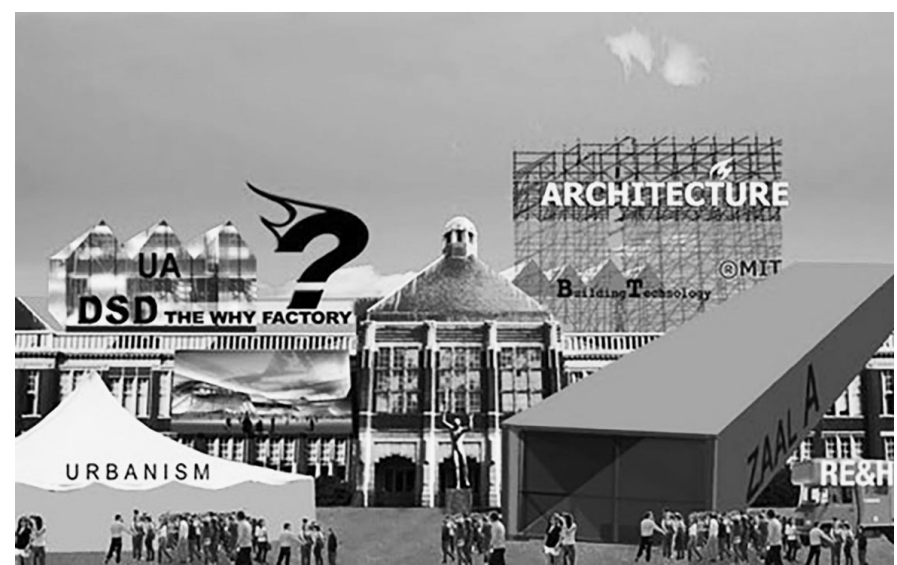

Fig. 2. BK City [source: urbanchange.eu].

and at the same time emphasizes the existence of the bound as a state of necessity (site, services, meaning, etc.). When applied to the larger extent, parasitic spatial form becomes parasitic architecture. "Parasitic architecture can be employed as a mediator between the changes in society on the one side and the urban systems on the other... The parasite provokes, explores and breaks open both physical and mental boundaries in order to offer opportunities for the elusive and new propositions. In this way parasitic architecture can start a process of changes" [5]. The experiments with architectural parasites are in most of the cases carried out on residential or office buildings; parasitic educational spaces are not common in practice.

Mobile spaces for crisis/emergency situations serve as the fastest solution in difficult circumstances occurred due to human conflicts, natural disasters or other significant damages in built environment at any scale (building, block, settlement, etc.) in which the users are suddenly faced with disturbances in basic needs fulfilment. Despite the necessity for immediate response problem solving still requires careful approach; involvement of the community and the respect to established pedagogical requirements are both necessary. Temporary solution offered for TU Delft Faculty of Architecture, after catastrophic fire in 2008, represents a good example of synergy between prompt reaction and adequate planning and realization. Supported by incredible solidarity, the educational structure of the Faculty was kept together in mobile tents at the campus' sport fields (Fig. 2).

If the isolation lasts for a prolonged period of time, i.e. if the crisis becomes chronic, it is then necessary to profoundly reorganize life and work on affected territory and to adapt the need for education and educational spaces. It may be concluded that mobile educational spaces represent the solution by which flexible architectural models fit into even more demographically flexible society of crisis area.

BMW Guggenheim Lab (Fig. 3) represents an example of mobile space for community based learning. The Lab offers different programs about urban life and aims to encourage active involvement of the community/participants. From 2011 to 2014, the Lab travelled to New York, Berlin, and Mumbai. The architectural structure, besides being movable, is light and flexible. The lower half resembles the Mediterranean loggia; it is an 


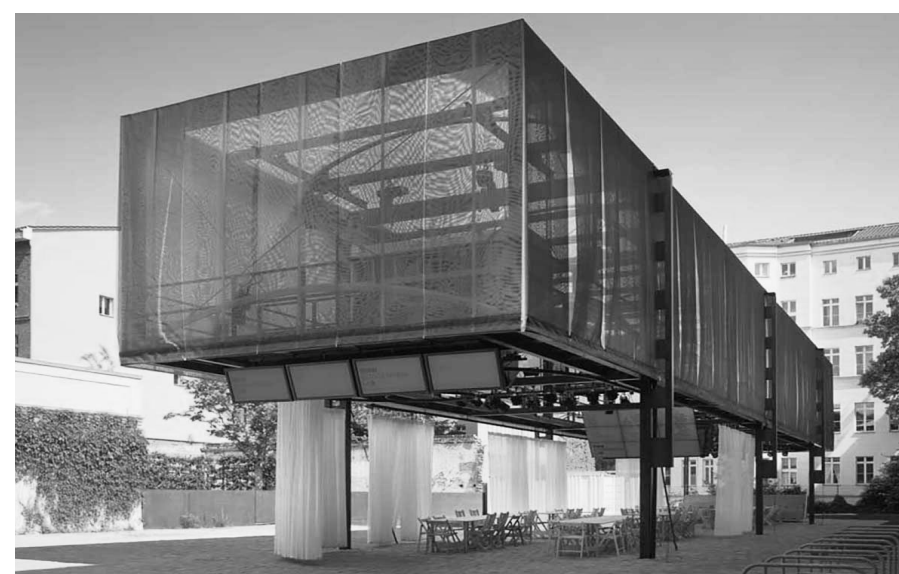

Fig. 3. BMW Guggenheim LAB in Berlin [source:openbuildings.com].

open space laterally confined with textile curtains. The ground space may, according to the Lab's programming needs, be transformed into a formal lecture setting, a stage for a celebratory gathering, or a workshop with tables for hands-on experiments [7].

According to the transportation means, mobile and temporary building systems are classified into three specific types: portable buildings which are transported whole and intact, where the method for transport is sometimes built-in within their own structure (wheels, hull); re-locatable buildings, transported in parts and assembled at the site almost instantly; and demountable buildings, transported in a number of parts that are later assembled on site [3]. Within these groups, the following categories are established: module, flat pack, tensile, pneumatic, and combined system [3]. In the group of portable buildings, mobile educational spaces on wheels and fully prefabricated shipping containers (Fig. 4) represent the typical examples.

Container architecture actualized the importance of structure in architecture by establishing the proportions and functions from the smallest element - the basic unit (container) until the level of a whole building. This is the architecture with no end, since container units allow stacking, growth and change in overall form [8]. Industrial, modular, mobile, additive, collapsible, loose, open and growing structure can be stacked in any direction - in lines, crosses, clusters or ridges, thus producing different forms of buildings, such as blocks, mats, pads, compounds, or cones. Universal design follows the modern stream, where architectural styles, tradition and high-tech architecture are all reconciled.

\section{ENIVIRONMENTAL SUSTAINABILITY AND IMPACT ON HEALTH}

Taylor [2] recognizes the significance of ecological quality of mobile architectural objects and notes that they must provide healthy and safe indoor environment, functional support, psychological comfort and aesthetic satisfaction. The most precise method for examination of ecological performance of mobile architecture, same as of conventional, is the analysis of behaviour through all life cycle phases. However, by comparing

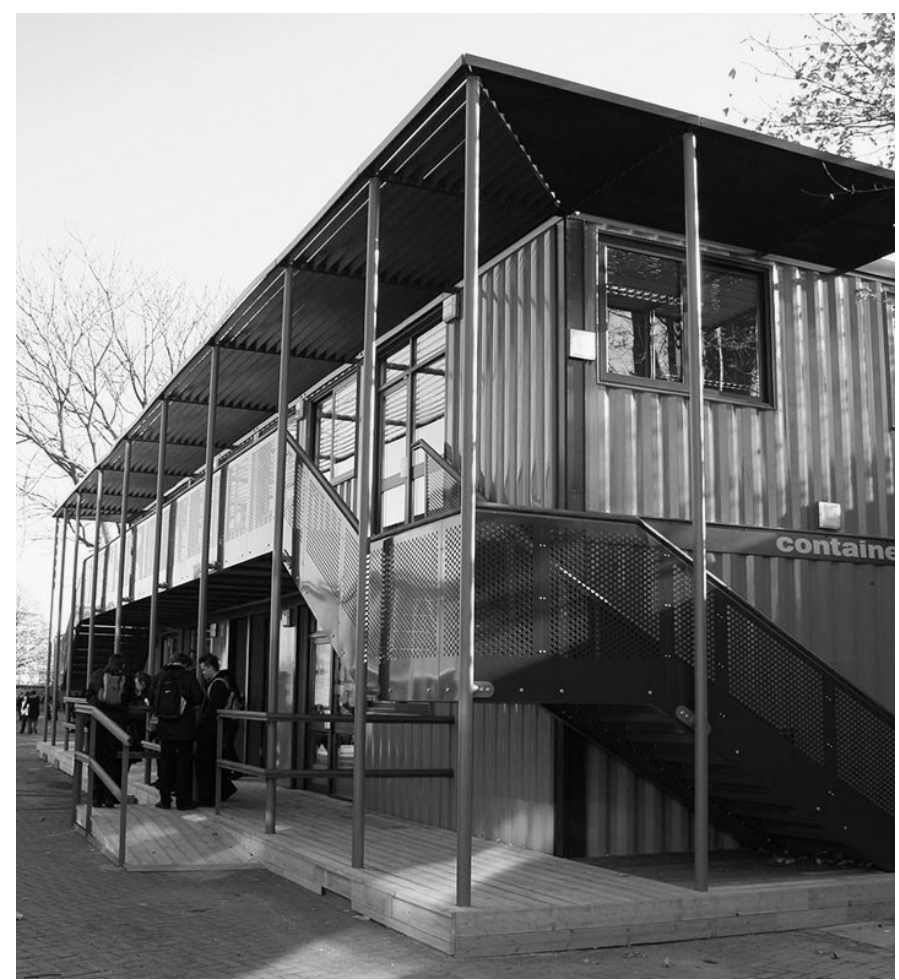

Fig. 4. Morpeth school [source: www.containercity.com].

life cycle of a mobile structure with the cycle of a conventional - static and on-site built structure, the important differences which occur during "preparation for construction" (on-site), "construction" (on-site), "use and maintenance" and "end of life" phases may be recognized.

Because mobile architectural objects intended for education are prefabricated structures, the activities belonging to on-site "preparation for construction" and "construction" are abridged; accordingly, emergent environmental impacts are reduced down to minimum. In this respect, it seems more appropriate to rename these phases to "preparation for installation" and "installation". The mentioned reduction of negative impacts relates to: scope of work with ground; existing vegetation treatment; infrastructural services provision; energy and water utilization; construction waste production; air, water and land pollution; and noise and dust generation. On the other hand, and regardless of the place, the production process itself entails consumption of resources and consequent ecological reflections which cannot be ignored.

Materials used for mobile structures are different from those selected for solid, permanent buildings; the application of metals, plastic and other high-tech and light materials is prevailing. Concerning the characteristics of applied materials, and before bringing final judgement about the overall ecological quality of a mobile structure, it is necessary to examine their life cycle as well. Generally, the phase of material production is considered as the most critical; the application of materials with recycled content cuts negative impacts occurring in this phase and is hence broadly recommended.

Considerable differences between static and portable educational objects occur during "use and maintenance". In this phase, 
per contra, the quality of mobile structure is more questionable in comparison with standard building. Even though the mobile spaces can be equally efficient in terms of utilization of water and energy (and optionally equipped with energy generation systems), and with the same established relationship between formed artefact and its environment (in regard to microclimatic changes and natural mechanisms' disturbance, light pollution, etc.), the issues concerning indoor environmental quality - day lighting, ventilation and indoor air quality, are often problematic and thus require special attention. For example, the problems found in temporary classroom trailers are commonly linked to heating, cooling, air-conditioning and ventilation systems, resulting in microbial contamination of indoor air. The same negative consequences occur in portable spaces without these systems; accumulation of indoor pollutants again leads to health problems [9]. When temporal purpose turns into a long-lasting utilization, new problems with the maintenance arise [9]. In addition to ecological and health problems related to the utilization of mobile structures, Chan emphasized the importance of socio-psychological factors and concluded that the impact of portable classrooms on teaching and learning still needs to be examined through experimental studies [10].

Since mobile educational structures are prefabricated, they allow for simple dismantling, recycling or re-use. In comparison with conventional demolition and later disposal this "end of life" scenario accounts for ecologically preferable option.

Mobile educational objects are universal; consideration of the context is not taken into account in their design, which directly opposes one of the main principles of sustainable design - the adjustment to local/regional characteristics. It should also be noted that there is an on-going debate about the positioning of mobile spaces in regard to static educational facilities, as stated in [9].

Author Robert Kronenburg suggests that a lot of effort needs to be put both in correct design of mobile architectural objects and in moving them from place to place. "And moving anything around is not sustainable. But when you are actually saving the building permanently which will be otherwise wasted or demolished afterwards, thus counteracting the cost of movement, there's always an equation between how much you save and how much it costs to relocate, and also how much resources it saves to make a new building. So the best way to do it more sustainably is to make your building as light as possible, very compact, which makes it a lot more economical to relocate. The lightest buildings that can be moved in compact form are the most sustainable. That's where portable architecture comes in" [11].

\section{ECONOMIC SUSTAINABILITY}

In general, mobile architectural units are considered as a quick, easy and economically feasible method for the integration of flexible architectural models into changeable societal conditions. Economic viability of a mobile structure can be determined by using one or more of generally accepted methods of economic evaluation based on the analysis of cost optimization, the analysis of cost and impact, or the analysis of cost and ben- efits (CBA). Despite the doubts and complaints regarding quantitative evaluation of individual investment projects on macro level and the accuracy and reliability of cost assessment, there stands the fact that CBA remains the most acceptable and the most commonly used method for the analysis of social investment projects [12].

In the study of economic viability of mobile container structures intended for crisis areas, by taking into account all indirect impacts and related social effects, it was found that advantages of this kind of construction manifest through operational cost reduction (for example, through savings in energy consumption, because of achieved energy efficiency) and reduced construction time (because the time needed for delivering, installing and putting the structure into operation have been reduced to a few days), which also means savings in required workforce and materials (because of the flexibility in choice and the possibility of using the disassembled object for other purposes). Economic benefits can also be achieved by taking care of vulnerable people; this is the greatest benefit that communities can reach, as it relates to the rapidity of saving lives and the prevention of environmental impacts on injuries, illnesses and mortality rates, all of which are the issues that require special attention in crisis areas [12]. Analogously, confirmed economic sustainability of mobile containers may be transferred to other types of mobile educational spaces, due to similar characteristics in regard to installation and operation. On the other hand, each type is characterized by distinct economic (as well as social and environmental) benefits in regard to specific purpose.

\section{CONCLUSION}

Mobile spaces enable the implementation of mobile educational concept and provide the response to emerging needs for education in different situations and locations. Because of their basic characteristics, these structures may be considered as simple, quick and almost universal solution.

At first glance, mobile architectural objects intended for education respond to social requirements in a proper way, and may even be seen as socially supporting, for example when applied in crisis areas or situations. However, the transition from temporal to more permanent utilization for specified learning purpose brings the justification of these spaces into question. The analysis of the mobile learning types, defined and presented in this paper, shows that the continuous (long-lasting) utilization of mobile structures for basic learning spaces, such as classrooms, requires detailed research of the influencing socio-psychological factors, while in other cases it appears convincing. Furthermore, as study on sustainability shows, the ecological aspect of mobile learning structures, especially in domains of indoor air quality and comfort requirements, as well as their potentially problematic maintenance, may also oppose the justification of permanent utilization.

From all above said, it seems that for long-lasting utilization on a single location and for a single purpose it is more appropriate to plan and use modular instead of mobile structures. Both types share similar ecological characteristics derived from thelife cycle analysis, with the difference that modular spaces of- 
fer enhanced quality of indoor environment. Custom made design, adaptation to constraints and possibilities of the location, and thus more adequate response to its specificities, account for some of the advantages of modular over portable architectural structures intended for education.

The architecture of mobile educational structures actualizes many design questions. Relationship with the outside context, space dynamics and limitedness, technological innovation, flexibility and adaptability, privacy but not the isolation, etc., are all challenges for designers who deal with mobile architecture and educational spaces.

\section{REFERENCES}

1. Leander, K., Philips, N., Headrick Taylor, K. The changing social spaces of learning : Mapping new nobilities. Review of Research in Education, Vol.34. Nashville, 2010 [online, cited 22.08.2014]. http://peabody.vanderbilt.edu/departments/t1/teaching_and_learning_research/space_learning _ mobility/Leander_social spaces.pdf DOI: 10.3102/0091732X09358129

2. Taylor, A. Linking Architecture and Education : Sustainable Design for Learning Environments. Albuquerque: UNM Press, 2009. 471 p.

3. Kronenburg, R. Architecture in motion : the history and development of portable building. London, New York: Routledge, 2013. 328 p.

4. Kronenburg, R. Flexible : Architecture that responds to change. London: Laurence King Publishing Ltd, 2007. 240 p.

5. Pit, M., Steller, K., Streng, G. Parasitic architecture [online, cited 24.07.2014] http://www.gerjanstreng.eu/files/T02\%20essay\%20parasitic\%20architecture.pdf

6. Marini, S. Parasitical architecture [online]. Domus [cited 25.08.2014] http://www.domusweb.it/en/architecture/2010/05/10/parasitical-architecture.html

7. BMW Guggenheim Lab Berlin : Pfefferberg Complex [online]. Open Buildings [cited 27.08.2014]. http://openbuildings.com/buildings/ bmw-guggenheim-lab-berlin-pfefferberg-complex-profile-43968

8. Buchmeier, M.,Slawik, H., Tinney, S., Bergmann, J. [editors] Container Atlas : A Practical Guide to Container Architecture. Berlin: Gestalten, 2010. $256 \mathrm{p}$

9. Sprout spaces vs. cheap classroom trailers [online]. Modular Classrooms [cited 27.08.2014] http://www.modularclassrooms.org/sprout-spaces-vscheap-classroom-trailers/

10. Chan T. C. Do portable classrooms impact teaching and learning? Journal of Educational Administration, Vol. 47/3. Kennesaw, 2009. pp. 290-304.

11. Moldakhmetova, A. Flexible architecture : from mobility to adaptability/ An interview with Robert Kronenburg [online]. Future Urbanism [cited 27.08.2014] http://futureurbanism.strelka.com/interview/from-mobility-to-adaptability/

12. Aleksić, J., Mihajlović,V., Jovanović, T. Cost-benefit analysis of shipping container emergency shelters : the case study of the Republic of Serbia. Actual Problems of Economics, Vol. 8 (158). Kiev, 2014. p. 56-66.

\section{CONTACT DATA}

Julija Aleksić

E-mail: julija.aleksic@pr.ac.rs

Saja Kosanović

E-mail: saja.kosanovic@pr.ac.rs; kossanovic@gmail.com

Dragan Komatina

E-mail: komatinadragan@gmail.com

Eva Vaništa Lazarević

E-mail: eva.vanistalazarevic@gmail.com

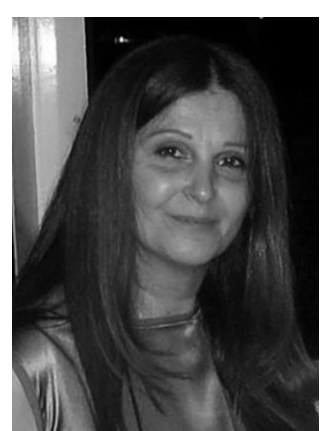

Julija Aleksić received $\mathrm{PhD}$ ih Architecture and Urbanism from the Faculty of Architecture and Civil Engineering in Banja Luka (in 2014), M. Sci. in Architecture and Urbanism from the Faculty of Architecture in Belgrade in 2010 and M. Arch. from the Faculty of Architecture and Civil Engineering of University of Priština in 1988. She is an Assistant Professor with the Department of Architecture of Faculty of Technical Sciences of University of Priština in Kosovska Mitrovica. She runs classes in architectural design, including studio work. Her research interest is mobile and prefabricated architecture. She is a practicing architect, interior and fashion designer.

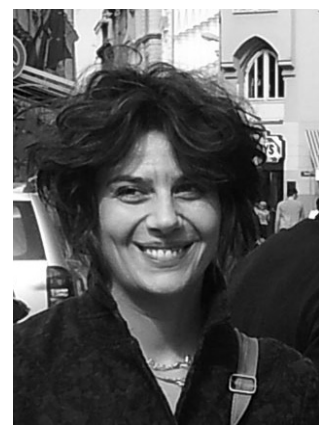

Saja Kosanović received $\mathrm{PhD}$ in Architecture and Urbanism from the Faculty of Architecture in Belgrade in 2012, M. Sci. in Architecture and Urbanism from the Faculty of Architecture in Belgrade in 2007, and M. Arch. from the Faculty of Architecture and Civil Engineering of University of Priština in 2000. She is an Assistant Professor with the Department of Architecture of Faculty of Technical Sciences of University in Priština in Kosovska Mitrovica. She is a visiting professor at the Faculty of Architecture in Belgrade. She lectures in architectural design, sustainable architecture and urbanism, environmental assessment of buildings, and tutors the design studio work. She is the author of the national system for environmental assessment of single-family houses, of the book Environmentally Friendly Buildings Introduction to Planning and Design. Her research interests are architectural design, environmental impacts of buildings, sustainability assessment methodologies, sustainable architectural and urban strategies, planning and design, architectural education. She is a practicing architect. Saja is a member of editorial/scientific boards of several journals and scientific conferences.

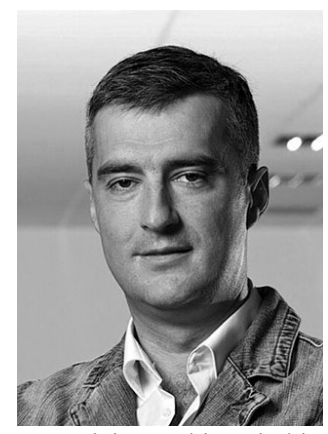

Dragan Komatina received $\mathrm{PhD}$ from the Faculty of Civil Engineering, Department of Architecture in Podgorica in 2010, M. Sci. in Architecture and Urbanism from the Faculty of Architecture in Belgrade in 2003 and M. Arch. from the Faculty of Architecture and Civil Engineering in Priština in 1997 .

$\mathrm{He}$ is an Assistant Professor with the Faculty of Architecture of University of Montenegro in Podgorica. Dragan lectures in architectural analysis, architectural and computer graphics, residential buildings, health facilities and architectural details, and tutors the design studio work. His research interest is architectural design. Dragan is a practicing architect in his own design bureau in Podgorica: Studio K. Dragan has been awarded several international architectural-urbanistic prizes.

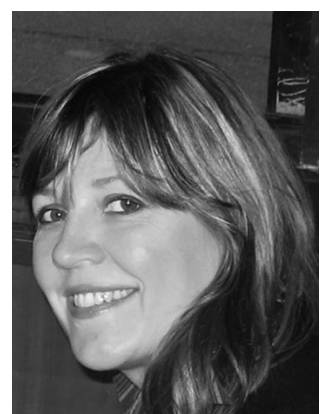

Eva Vaništa Lazarević received $\mathrm{PhD}$ in $\mathrm{Ar}$ chitecture and Urbanism from the Faculty of Architecture in Belgrade in 1997, M. Sci. in Architecture and Urbanism from the Faculty of Architecture in Zagreb in 1990 and M. Arch. from the Faculty of Architecture in Zagreb in 1983.

Eva is a Professor with the Faculty of Architecture of University of Belgrade. She is the author of two awarded books: Urban Rehabilitation (1999) and Urban Renewal in the New Millennium (2003). Her research interests are protection of cultural heritage, urban regeneration and renewal, urban design and planning, sustainable development, brownfield. She is a practicing architect in her own design bureau in Belgrade: Atelier Eva Vaništa Lazarević.

Eva is a winner of multiple international and national prizes in architectural-urbanistic competitions. She is Director and main organizer of the International Conference Places and Technologies 2014. Eva is an Editor of several professional and scientific journals. She is a founder of the following NGOs: Agency Urban_Lab, Urban Regeneration. She participated in the preparation of the General Plan of Belgrade and Spatial Plan for Serbia. 